\title{
Microwave Assisted Reactions in Organic Chemistry: A Review of Recent Advances
}

\author{
Jolly Jacob ${ }^{1}$ \\ ${ }^{1}$ Department of Applied Sciences, College of Arts \& Sciences, Abu Dhabi University, Abu Dhabi, UAE \\ Correspondence: Jolly Jacob, Department of Applied Sciences \& Mathematics, College of Arts \& Sciences, Abu \\ Dhabi University, P.O. Box 59911, Abu Dhabi, UAE. E-mail: jolly.jacob@adu.ac.ae
}

Received: October 17, 2012 Accepted: October 31, 2012 Online Published: November 20, 2012

doi:10.5539/ijc.v4n6p29

URL: http://dx.doi.org/10.5539/ijc.v4n6p29

\begin{abstract}
Revolution in organic compound synthesis has been promoted by microwave assisted organic syntheses (MAOS) by which small molecules are built up into large polymers in a fraction of time. The need for different organic compound libraries for drug discovery, biomaterial development, automated library screening; proteomics etc has supported the emergence of innovative technologies for rapid combinatorial organic synthesis using MAOS synthesis. In previous reviews on this subject the focus of MAOS has been on the process of MAOS reactions rather than the importance given to the related applications. This review focuses on solid-phase synthesis, biopolymer synthesis, applications in proteomics, parallel processing in microwave reactors and automated library generation by means of sequential microwave irradiation methods. This article has discussed the different applications of Microwave assisted synthesis of organic polymeric compounds most thoroughly by focusing on aspects of speed, reproducibility and scalability. From this review it is clearly identified that independent on the type of organic material, data consistently points out to MW as a novel and powerful tool which has enable synthesis of a number of new compounds and presents the need for future research in this area.
\end{abstract}

Keywords: microwave assisted organic synthesis, MW irradiation in organic chemistry, organic solid phase synthesis, biopolymer synthesis, automated library generation, proteomics and organic synthesis

\section{Introduction}

Revolution in organic compound synthesis has been promoted by microwave assisted methods by which small molecules are built up into large polymers in a fraction of time when compared to thermal methods ensuring the acceptance of Microwave assisted irradiation reactions as a valuable tool for acceleration of a wide variety of organic molecules development (Mavandadi \& Pilioti, 2006; Tsoleridis et al., 2011). The advent of microwave assisted technology in organic chemistry dates back to the mid 1980s and since the 1990s there has been a significant increase in the number of publications on Microwave Assisted Organic Reactions (MAOS) (Langa et al., 1997; Strauss \& Trainor, 1995; Diaz-ortiz et al., 1997; Lidstrom et al., 2001; Kappe et al., 2005; Wathey et al., 2002) due to increased benefits associated with the process. The promotion of microwave assisted reactions in organic chemistry has improved the speed, reduced cost, reduced energy spent making it a sustainable process and is widely heralded as "green chemistry" measures (Tsoleridis et al., 2011; Prasad et al., 2012) whose applications are promoted today to minimize the use of non renewable resources as well as polluting solvent, to reduce generation of secondary products which are often toxic and to reduce the emission of harmful gases (Wang et al., 2011; Tucker, 2010; Erdmenger et al., 2010). Microwave assisted reactions in organic chemistry achieve the same by ensuring facilitation of faster reactions under bulk conditions as well as promoting reduction of reaction time (Erdmenger et al., 2010).

The need for different organic compound libraries for drug discovery, biomaterial development, automated library screening, proteomics etc has supported the emergence of innovative technologies for rapid combinatorial organic synthesis using MAOS synthesis (Lidstrom \& Tierney, 2005; Kappe et al., 2005). The ability to reduce reaction time from days and hours to minutes using microwave assisted reactions has promoted advent of microwave technology in combinatorial chemistry (Santagada et al., 2004; Kappe, 2004) and drug discovery (Sekhon et al., 2010; Santagada et al., 2009) as there is reliance on generation of large number of compounds whose production has been diversified as well as enhanced due to MAOS as there is increased production of cleaner reactions and more pure products (Bogadal et al., 2003; Mosely et al., 2007). This importance given to 
microwave assisted reactions in organic chemistry has resulted in a number of reviews on this subject. In the reviews by Lidestrom (2001), Ravichandran and Karthikeyan (2011) and Surati et al. (2012) the focus of MAOS has been on the process of MAOS reactions rather than the importance given to the related applications. Hence this review focuses on the latest advances in this area after giving a brief introduction on the Microwave process as well as the equipment used. Some of the novel areas where MOAS has been applied have been focused including solid-phase synthesis, biopolymer synthesis, applications in proteomics, parallel processing in microwave reactors and automated library generation by means of sequential microwave irradiation methods.

\section{Microwave Irradiation Process and Advances in Methodology}

Microwave irradiation is found to be faster and more effective than conventional methods as it employs both microwave heating technology and combinatorial chemistry applications (Larhead \& Hallberg, 2001). MWs consist of electromagnetic radiation which operates at the frequency between 0.3 and $300 \mathrm{GHz}$. MWs with the frequency range of 2-8 GHz specifically used for domestic and synthetic purposes to prevent the interference with telecommunications and radars. For example, MWs with the frequency of $2.45 \mathrm{GHz}$ used in most of the house-hold ovens. This technique has been considered as an effective synthetic tool, as it acts fast, produces high outcomes \& low derivatives. Moreover, it can be easily scaled-up without harmful side-effects (Mingos et al., 1997). The MW heating process operates under high pressure conditions in order to make a reaction faster and limit side reactions. (Mingos et al., 1997). The research areas that rely on the development of large libraries of compounds, such as combinatorial chemistry (Pon-On et al., 2007; Pande et al., 2009; Nuchter et al., 2001) and drug discovery (Sekhon et al., 2010; Santagada et al., 2009) have been motivated due to the ability of microwave heating process in reducing the reaction time.

MW-assisted reactions can be carried out quickly and the end products of these reactions were identified to be pure (Mingos et al., 1997). So it could enhance and diversify the capabilities of the synthetic chemist. With the longer reaction time, the number of secondary products was found to be high. If one of the reactants is liquid it plays the role of a solvent and take up MW to heat the reaction mix, so that the reactions could be carried out under solvent-free environment (Mingos et al., 1997; Li, 1993). The researchers have proposed a wide range of hypotheses to illustrate the role of microwave irradiation in accelerating the reaction rate. But it is very difficult to define the widely accepted reason for this role (Perreux \& Loupy, 2001). A special microwave effect is found to be effective and suitable for a wide range of chemical reactions irrespective of its origin/existence (Lidstrom et al., 2001; Larhead \& Hallberg, 2001; Nobrega et al., 2012)

Hayes and Collins (2004) introduced an alternative method to carry out microwave assisted organic reactions. This method is known as "Enhanced Microwave Synthesis" (EMS) where compressed air was used to cool the reaction vessel during irradiation, as a result, the reaction mixture would get more energy during the reaction times. In the case of Conventional Microwave Synthesis (CMS), the high initial microwave power would rapidly increase the bulk temperature (TB) to the expected set point and the temperature reached this point, there would be a decrease in the microwave power. By this way, the desired bulk temperature could be controlled. This method has been used to support a protease inhibitor discovery project, wherei different kinds of $\alpha$-keto amides have been synthesized and the resultant research is helpful to discover treatments for stroke, Alzheimer's disease, and muscular dystrophy (Chen \& Deshpande, 2003). In an earlier procedure, acyl chlorides were coupled with isonitriles to produce $\alpha$-Keto imidoyl chloride intermediates as identified in the following Figure 1. Upon hydrolysis, $\alpha$-keto amides were synthesized from these intermediates. In the case of traditional approach, it would take around 2 to 6 hours to complete this reaction. However, with EMS approach, the same reaction could be completed within 2 mins. Furthermore, the product yield was identified to be higher with this method (21-74\%).

In comparison with microwave heating, EMS could release more amides from the solid-phase resin (Humphrey et al., 2003). Katritzky et al. (2003), reported the role of EMS in synthesizing bistriazoles with the use of 1,3-dipolar cycloaddition reactions of 1,4-bis(azidomethyl)benzene with monoacetylenes. This Cyclo addition would occur at one of the azido moieties only, if the diazide is coupled with carbamoylpropiolate under $55^{\circ} \mathrm{C}$ at $120 \mathrm{~W}$ for half an hour. However, with higher temperatures and irradiation powers, the reactants will decompose. However, using EMS, Katritzky et al. (2003) have successfully produced bistriazole by coupling the diazide with butynoate at $120 \mathrm{~W}$ and $75{ }^{\circ} \mathrm{C}$ for an hour and they have isolated the major isomer in $54-65 \%$ yields. This methodology is identified to be one of the advances of microwave assisted organic synthesis. Having discussed the principle behind microwave irradiation and the related advantages, the review focuses on the applications of the same. 


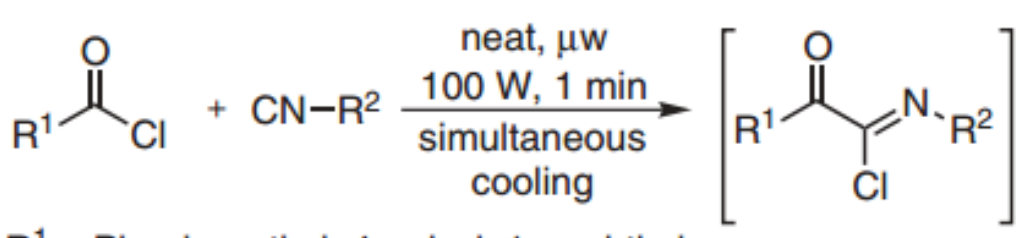

$\mathrm{R}^{1}=\mathrm{Ph}$, phenethyl, 4-anisyl, 1-naphthyl

$\mathrm{R}^{2}=n-\mathrm{Bu}, \mathrm{Bn}, \mathrm{Cy}$<smiles>[R]NC(=O)C([R])=O</smiles>

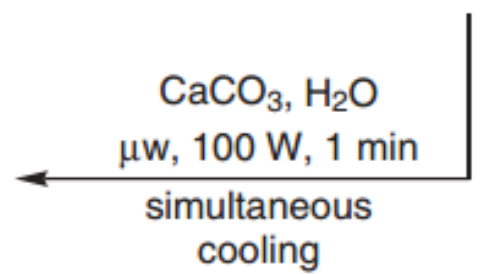

$$
21-74 \%
$$

Ref. 6

Figure 1. Improved synthesis of $\alpha$-Keto amides by Enhanced Microwave Synthesis (EMS)

The importance of microwave assisted reactions in promoting solvent free conditions has been researched in a number of laboratories (Tierney \& Lidstrom, 2005; Lidstrom et al, 2001). Solvent free organic synthesis is a well promoted process as it is identified to be an environmentally friendly process which combines the selectivity which is associated with microwaves along with procedures which is waste free (Kappe, 2004; Hayes, 2004; Varma, 2001; 2006). There are broadly three different types of solvent free reactions which can be carried out including those which use neat reactants, those which use solid liquid phase transfer and those which use solid mineral support. Some reactions under each of the above mentioned conditions are identified below.<smiles>[O+]c1ccccc1</smiles><smiles>Clc1nc(Cl)nc(Cl)n1</smiles>

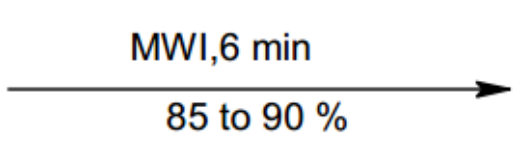

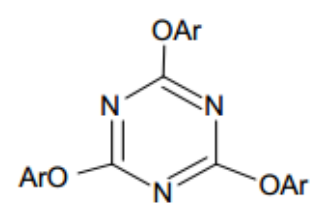

Figure 2. Formation of substituted triazines (Seijas et al., 1999; Dahmani et al., 1998)

Aromatic nucleophilic substitutions are carried out using sodium phenoxide and 1,3,5-richlorotriazine under microwave irradiation.<smiles>O=C1NC(=O)c2ccccc21</smiles>

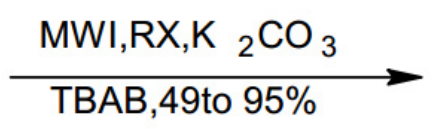<smiles>[R]N1C(=O)c2ccccc2C1=O</smiles>

Figure3. Synthesis of $\mathrm{N}$-alkyl phthalimides using phthalimide, alkyl halides, potassium carbonate and TBAB

(Bogda et al., 1996) 
<smiles>[R]CN1CCN([R])CC1</smiles>

Figure 4. Piperidines and Chloroalkanes react in the presence of silica as the solid support under microwave irradiation (6-10 $\mathrm{min}$ ) (Heravi et al., 2004)

\subsection{Polymer Synthesis}

An emerging area in biopharmaceutical research involves design and synthesis of on-demand biomaterial research (Williams, 2009) as they not only are important as drug carriers but also act as more complex systems who have the ability to interact with a number of biological systems invivo (Kohn et al., 2007). Technology transfer for biomaterial synthesis has been challenging due to inability to reproduce conditions during scale up (Armstrong et al., 2006; Danson et al., 2004) but with the advent of Microwave assisted technology synthesis or organic biopolymers has been accomplished which is reviewed in this section by focusing on mainly on two applications Poly Lactic Acid (PLA) and Poly caprolactone (PCL). Controlled solvent-free synthesis and modification in polymer materials can be rapidly and effectively done with the help of microwave heating using large scale reactors as identified in Figure 5 (Ebner et al., 2011; Guo et al., 2009; Iannelli \& Ritter, 2005; Roy et al., 2009; Sosnik et al., 2010; Wang et al., 2008).

The biomedical applications of PLA, polyester have been extensively studied by the researchers. The first microwave assisted organic synthesis of d,l-Lactic Acid was carried out with SnOct as catalyst by using toluene as a solvent (Blokzijl et al., 1993). The end products were found to have 39-67 kDa of molecular weight and low polydispersity index (1.3-1.7) produced in a reaction time of 15 and $60 \mathrm{~min}$, carried out under low power $(85-170 \mathrm{~W})$ and at isothermal conditions $\left(130^{\circ} \mathrm{C}\right)$. The reaction was later standardized by Wang et al. (2008) to produce Poly DL-Lactic Acid (molecular weight of $100 \mathrm{kDa}$ ) which as carried out under irradiation power $(255 \mathrm{~W})$ to obtained higher yields $(90 \%)$ However, these conditions were identified to enhance the degradation of polymers needing further modification of the MAOS process. Following this study, the role of over-irradiation in developing the harmful effects in terms of both power and time on biopolymer production was focused (Sosnik et al., 2010). If the reaction is carried out under non-isothermal conditions, high rate of monomer degradation could be observed within six minutes (Kirschner, 1994; Ebner et al., 2011).

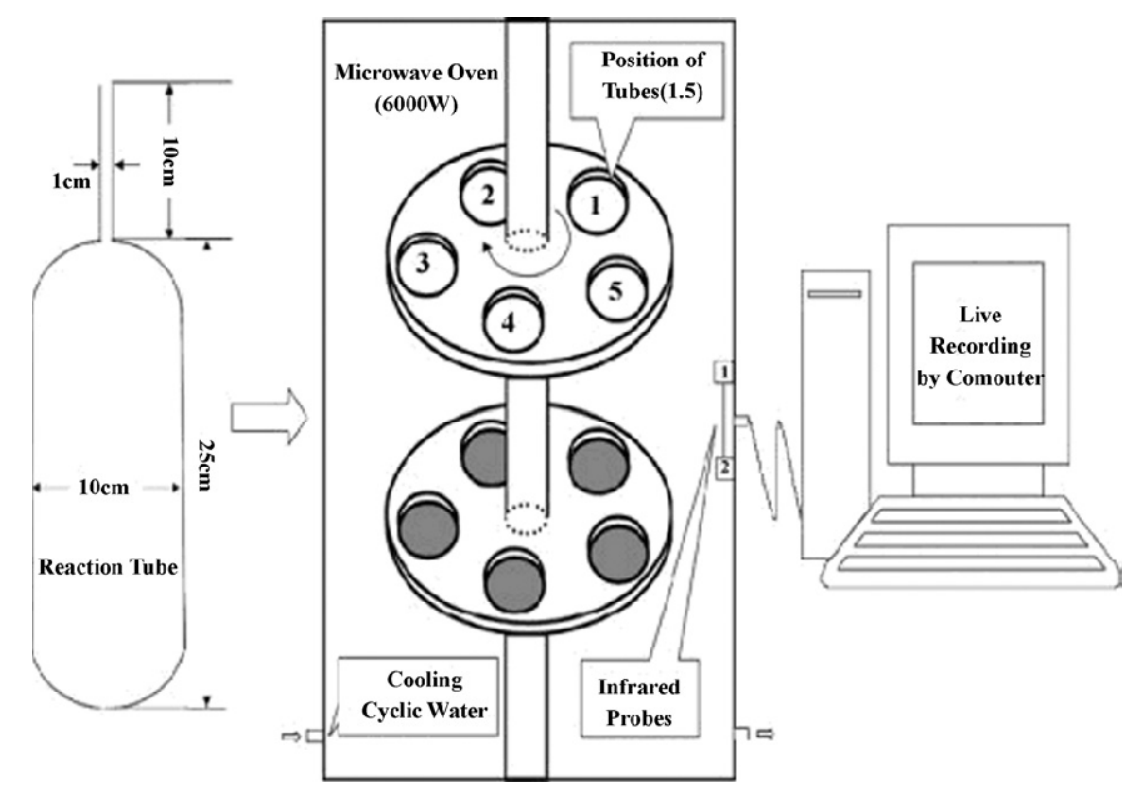

Figure 5. Schematic illustration of polymerization reactor for the large-scale microwave-assisted reaction process for polymer synthesis (Xu et al., 2010) 
Poly ( $\varepsilon$-caprolactone) (PCL) is a semi crystalline and hydrophobic poly (ester) used in various biomedical devices as it is biocompatible in nature (Seijas et al., 2007; Seijas et al., 1999). While comparing the conventional and microwaves techniques it was identified that conversion, measured by means of viscosity build-up, and number-average molecular weight of poly ( $\varepsilon$-caprolactone) were similar for both processes and did not indicate advantages relating to the use of microwave irradiation (Lee et al., 1997). Since then, various researchers such as (Nuchter et al., 2004; Ramesh et al., 1994; Xu et al., 2000; Pileni \& Langmuir, 1997) began to focus on the effects of various initiators such as carboxylic acids and catalysts such as lanthanide halides, $\mathrm{Zn}$ powder and lipase on PCL. The outcomes of these studies contradict the conclusion arrived at earlier and in these studies, the researchers carried out the reactions under bulk conditions with SnOct as a catalyst. Instead of catalysts, carboxylic acids such as benzoic acid and chlorinated acetic acid were usedto polymerise CL (Bogdal, 2005) who did not monitor the temperature condition of this reaction. This initiator (carboxylic acid) was added to the polymer chain along with a mix of CL and benzoic acid (25/1 molar ratio) which was irradiated at $680 \mathrm{~W}$ for four hours. wherein monomers with polar functional groups were polymerised successfully (Bogdal, 2005).

As the MW-assisted reactions are rapid in nature, it is easy to carry out these reactions under normal atmosphere to generate high yields $(90 \%)$ with the high molecular weight of $200 \mathrm{kDa}$ (Illman, 1994). Nikolic et al. (2011) found out that within thirty minutes MW-assisted reactions could produce products with molecular weight of up to $310 \mathrm{kDa}$ at $100^{\circ} \mathrm{C}$ solving the problems faced by Wang et al. (Herrero et al., 2008). A domestic microwave oven has been recently modified by Zhang et al. (2011) to facilitate unremitting microwave irradiation ( $90 \mathrm{~W}, 10$ $\mathrm{min}, 0.56 \mathrm{wt} \%$ SnOct resulting in another solution to the problem. Since then, there has been a more rapid increase in reaction temperature. Moreover, reaction rates and yields of the polymer/biomaterials reactions can be improved with the use of microwaves. On the other hand, it is necessary to investigate the fundamental aspects of the microwave assisted irradiation process in detail (Hren et al., 2008). Nakamura et al. (2010) pointed out that the dielectric characteristics of the reaction mix would decrease over time which attracted more and more researchers to focus more on these parameters ( Zhang et al., 2009; Nikolic et al., 2011).

\subsection{Solid Phase Organic Synthesis}

Advantages of microwave-assisted synthesis are mostly embodied in synthesis procedure under solid-state condition. With the use of microwave irradiation Besson, Guillard, and Rees (2000) carried out the multistep synthesis of thiazoloquinazolines in solution which has become a valid example for the application of microwaves to synthesize organic products in the presence of solvents. Compared with traditional solution-phase chemistry, solid-phase synthesis in the presence of microwave irradiation has gained increasing attention from practitioners of combinatorial chemistry due to some advantages, like simplification of reaction work-up and product isolation, affinity and specificity of reaction (Bremer, Szewczyk, Baird, \& Dervan, 2000), rate-enhancements and the higher product yields (Larhed \& Hallberg, 2001; Kirschning et al., 2001).

Stadler and Kappe (2001) used multimode microwave reactors in their study by attaching aromatic carboxylic acids to chloromethylated polymer-supported resins in the absence of solvent as identified in the following Figure 6. This cesium carbonate method has been carried out using microwave irradiation where in comparison to conventional heating methods, the microwave assisted methods were found to be more advantageous in terms of rate-accelerations, loadings and reaction time. In traditional method (heating at $80^{\circ} \mathrm{C}$ ) reaction time was 12 to $48 \mathrm{~h}$ while Microwave assisted heating at $200{ }^{\circ} \mathrm{C}$ and open glass vessels, led to a phenomenal decrease in reaction time of 5-15 min. In this case, the polymer-supported resins were not degraded even under prolonged microwave irradiation at $200{ }^{\circ} \mathrm{C}$. Due to these advantages in terms of product yields and rate-enhancements in relation to conventional method, most of the practitioners prefer to use microwave-assisted solid-phase organic synthesis in organic combination industry making it a popular technique among practitioners. 


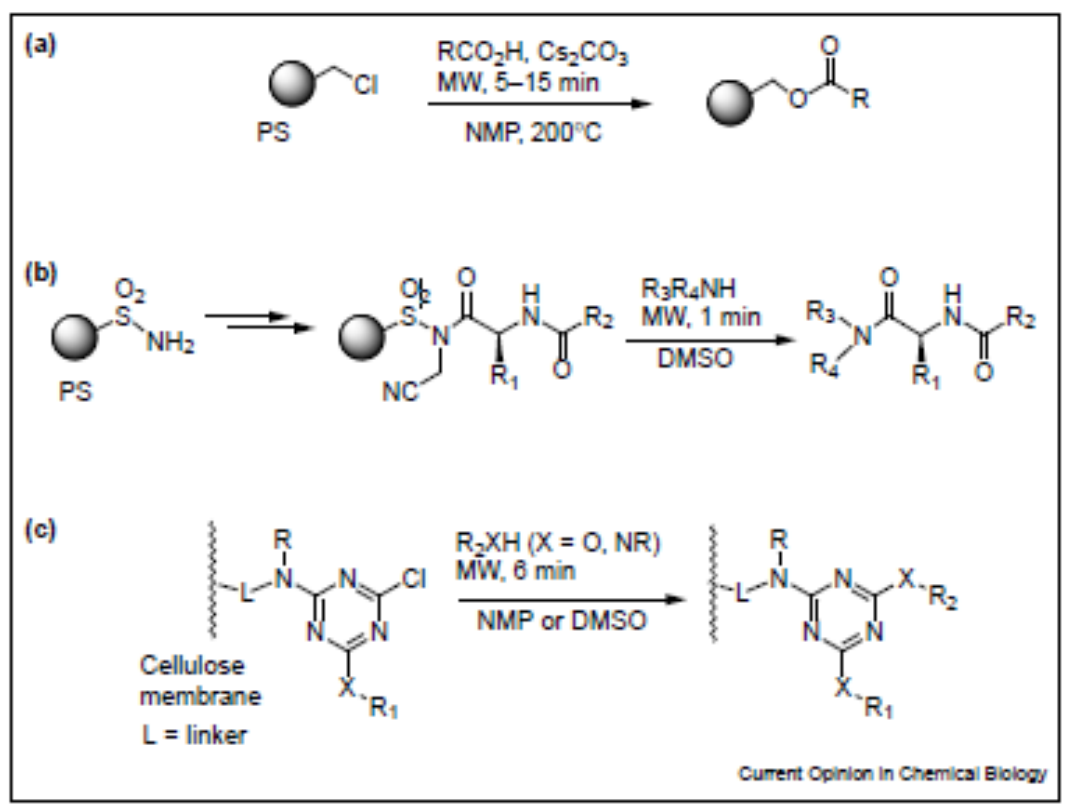

Figure 6. Microwave-assisted solid-phase organic synthesis (Kappe, 2002)

The above figures shows the process where there is attachment of carboxylic acid to chloromethylated PS resins by making use of the caesium carbonate method following which there is cleavage of $\mathrm{N}$-acytelated amino acids which are attached to the resin. Finally there is microwave supported substitution of chlorine atom in the monochlorotriazines.

\subsection{Parallel Processing in Microwave Reactors}

In recent years, many researchers have attempted to carry out microwave-enhanced solid-phase organic synthesis (SPOS) in a parallel way. For example, Glass and Combs (2001) have attempted to carry out microwave-assisted resin cleavage. In this study, they activated the linker with the use of bromoacetonitrile based on safety catch principle of Kenner to cleave $N$-acylated amino acids that have been attached to 4-sulfamylbutyryl resin. One of the first examples of parallel processing using 96-well plates was carried out by Cotterill et al. (1998), who presented microwave-assisted parallel synthesis of pyridine libraries. Following this study, various studies (Kappe, Kumar, \& Varma, 1999; Varma \& Kumar, 1999; Usyatinsky \& Khmelnitsky, 2000; Olsson, Hansen, \& Andersson, 2000) have proposed multi-component strategies to synthesize heterocyclic components.

With different reaction conditions such as microwave (domestic oven) and traditional oil-bath heating, the researchers have examined the cleavage rates in DMSO for diisopropylamine and aniline. While using microwave approach, it would take 15 mins to cleave uncreative aniline at $140{ }^{\circ} \mathrm{C}$. While using traditional oil-bath heating $\left(80^{\circ} \mathrm{C}\right)$, it would take at least one hour for the same. However, there is no report on kinetic comparison of reaction rates of both microwave and conventional heating at $140^{\circ} \mathrm{C}$. Based on this principle, few researchers carried out the automated parallel synthesis of an 880-member library with the use of 96-well plates. Ten different amino acids (R1) (each of them carries a diverse acyl group (R2)) and 88 different amines $(\mathrm{R} 3 \mathrm{R} 4 \mathrm{NH})$ were used in this reaction. It was observed that under domestic microwave oven condition, a $20^{\circ} \mathrm{C}$ temperature gradient would exist between the inner and outer wells of the 96-well plate. But, it was observed that this gradient did not affect the particular chemistry (Glass \& Combs, 2001).

Wenschuh et al. (2000) have synthesised a library of trisamino- and amino-oxy-1,3,5-triazines with 8000-members in their study, by carrying out microwave-assisted nucleophilic substitution at cellulose-membrane-bound monochlorotriazines. Microwave assisted substitution of the chlorine atom in monochlorotriazines is the major step in this reaction. Under atmospheric reaction conditions, the substitution reactions in amines and solutions of cesium salts of phenols could be carried out in 6 mins. But in the case of traditional approaches, the reactants should be heated at $80^{\circ} \mathrm{C}$ for $5 \mathrm{~h}$ or the reaction time should be long(four days) for the substitution reactions. On $18 \times 26 \mathrm{~cm}$ cellulose membranes, the researchers have carried out the SPOT-synthesis process to assemble the triazines subsequent to cleavage with trifluoroacetic acid vapour. Scharn 
et al. (2001) have treated other halogenated heterocycles, such as 2,4,6-trichloropyrimidine, 4,6-dichloro-5-nitropyrimidine and 2,6,8-trichloro-7-methylpurine in the same way, to synthesize macrocyclic peptidomimetics.

The first report on application of dedicated parallel microwave reactors for SPOS has been given by Strohmeier and Kappe (2002). In this report, they have carried out the microwave assisted synthesis of Knoevenagel products with the use of resin-bound $\beta$-ketoesters. In this reaction, microwave assisted acetoacetylation of PS Wang resin with various $\beta$-ketoesters in 1,2-dichlorobenzene was carried out at $170{ }^{\circ} \mathrm{C}$ for $1-10$ min to synthesize resin-bound 1,3-dicarbonyl compounds. However, in the case of conventional approach, the same reaction should be carried out for hours together. While performing subsequent microwave-assisted Knoevenagel reactions with different aldehydes, the researchers have observed rate enhancements.

In respect to parallel synthesis, compound libraries are commonly prepared sequentially in an automated singlemode instrument with full control of each reaction or in a multimode instrument performing parallel reactions in one irradiation experiment only. Additionally, it has been shown that it is possible to directly scale reaction conditions from single mode small-scale to multimode larger scale microwave reactors (Kremsner \& Kappe, 2006). Thus it is identified that parallel processing can be made possible by making use of microwave technology for synthesizing organic compounds and is a growing field of importance.

\subsection{Automated Library Generation}

Parallel set-ups are useful to carry out a microwave-assisted chemical reaction within a short timeframe. However, there will be limited control over each reaction vessel regarding temperature/pressure. Each reaction vessel will be kept under same irradiation conditions in parallel set-ups. The reaction temperature is found to be associated with dielectric properties of solvent. So it is necessary to use same amount of identical solvent in each vessel so as to maintain temperature (Gabriel et al., 1998). The process of automated library generation is a viable alternative to parallel processing.

The reaction conditions could be effectively controlled by irradiating each reaction vessel separately. This individual irradiation was useful to optimize the reaction parameters. While synthesizing a series of dihydropyrimidines through Biginelli multicomponent reaction, Stadler and Kappe (2001), used monomode reactor to carry out automated sequential microwave-assisted library synthesis as observed in the following Figure 7. To carry out this process, they used a set of $17 \mathrm{CH}$-acidic carbonyl compounds, 25 aldehydes, and 8 urea/thioureas. With the use of automated addition of building blocks and microwave irradiation, a sub-set of 48 analogs among 3400 possible dihydropyrimidine derivatives was synthesized. In this method, reagents were dispensed into the Teflon sealed reaction vessels with the use of a liquid handler and each sealed vial were moved in and out subsequent to irradiation with the help of a gripper. For most of the building block combinations, microwave heating of solvents and catalysts at $120^{\circ} \mathrm{C}$ for $10 \mathrm{~min}$ was found to produce isolated yield of $52 \%$ of dihydropyrimidines . Furthermore, this yield was obtained with $90 \%$ purity. i.e., within 12 h, the 48-member dihydropyrimidine library had been produced using unattended automation capabilities of the microwave synthesizer. Recently, Öhlberg and Westman (2001), Wilson, Sarko, and Roth (2001), Öhlberg and Westman (2001) and Wilson, Sarko, and Roth (2002) have reported the other applications of automated library generation in rapid lead discovery and lead optimization to illustrate the importance of microwave assisted technology in the field of proteomics. 


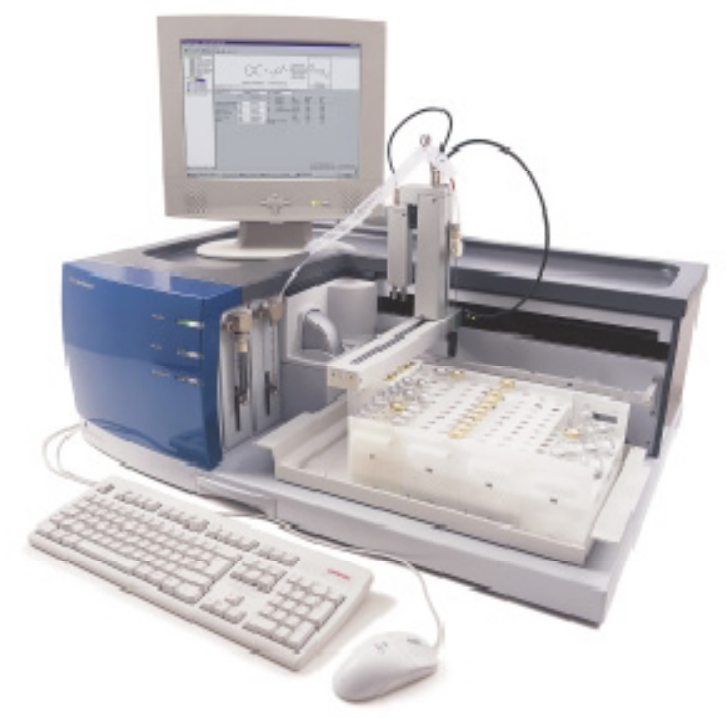

Figure 7. Monomode microwave reactor with an integrated robotic platform for automated use (Smith Synthesizer, Personal Chemistry AB) (Kappe, 2002)

\subsection{Applications in Proteomics}

Researchers began to apply microwave technology into proteomics so as to carry out enzymatic protein digestions (Lill, 2009; Zhao, 2010; Lill et al., 2007; Sandoval et al., 2007; Sandoval et al., 2008). This non-classical proteomics method is identified to have enhanced digest efficiency and sequence coverage, and also accelerate degradation rates (Lill , 2009; Zhao, 2010; Lill et al., 2007; Sandoval et al., 2007; 2008). The researchers termed these differences between conventional and microwave assisted digestions as non-thermal microwave effects (Perreux \& Loupy, 2001; 2006; Moreno et al., 2005; 2006). They have observed that the interaction between protein or enzyme and $2.45 \mathrm{GHz}$ electromagnetic field is responsible for these differences and macroscopic change in temperature has no role over them (Lill, 2009; Zhao, 2010; Lill et al., 2007; Sandoval et al., 2007; 2008). Besides the solution (Lill, 2009; Zhao, 2010; Lill et al., 2007; Sandoval et al., 2007; Sandoval et al., 2008), in-gel tryptic digests also demonstrated enhanced digest efficiency/sequence coverage (Sun et al., 2005; Juan et al., 2005). If we load digests with magnetic elements to enhance the microwave absorptivity of the irradiated solutions, similar improvements in terms of digest efficiency/sequence coverage could be observed (Y. Chen \& C. Chen, 2007; Lo et al., 2007; Li et al., 2007).

However, if there is no idea about exact internal reaction temperature, this type of reactions cannot be carried out or they may give incorrect outputs (Herrero, Kremsner, \& Kappe, 2008; Obermayer \& Kappe, 2010; Bacsa et al., 2008). A single-mode high field-density microwave reactor $(2.45 \mathrm{GHz}, 850 \mathrm{~W})$ along with internal fiber-optic temperature control had been used in the reactions to monitor the reaction temperature accurately in a small scale(0.5-2 mL) (Obermayer, Gutmann, \& Kappe, 2009; Gutmann et al., 2010). Most of the researchers have carried out the microwave-assisted proteomics studies in domestic microwave ovens without reliable reaction temperatures (Vaezzadeh et al., 2010; Hahn et al., 2009; Lesur et al., 2010). They have also used microwave instrumentation that has no internal probe to monitor the actual reaction temperature directly. Instead, they have used external IR sensors to monitor the surface temperature of the reaction vessel (Herrero, Kremsner, \& Kappe, 2008; Obermayer \& Kappe, 2010; Bacsa et al., 2008) reported unreliability of these sensors with highly viscous reaction mixtures.

Besides microwave-assisted proteomics, other scientific fields related to proteomics study are also identified with non-thermal microwave interactions on proteins, enzymes, or other biological samples. As an example, these effects are used in biocatalysis discipline (Réjasse et al., 2004; 2006; Yadav \& Borkar, 2009; Souza et al., 2009), DNA hybridization (Edwards, Young, \& Deiters, 2009) and the studies that evaluate enzyme stability with the use of microwave irradiation (Rejasse et al., 2007; Young et al., 2008; Izquierdo et al., 2007; Porcelli et al., 1997; La Cara et al, 1999). Recently, Laurence et al. (2000), H. Bohr and J. Bohr (2000), Pomerai et al. (2003) reported unfolding or structural changes in proteins with microwave irradiations and suggested the inclusion of 
the hazards from cell phones and domestic microwave ovens in the list of effects of non-thermal interactions on protein structure and enzyme activity as these equipments are being operated in the microwave frequency range $(\sim 800-2450 \mathrm{MHz})$. So despite the wide range of applications of MAOS in proteomics future research should make it necessary to examine the effects of microwave irradiation on protein structure and enzyme activity (Budi et al., 2005; 2007; 2008; Astrakas et al., 2011).

\section{Conclusion}

The fields of polymer science, bioinformatics, biotechnology as well as biochemistry have been attracted towards microwave assisted reactions in recent years. The chemical reactions can be effectively carried out with the use of microwave ovens. Rapid lead generation and optimization can be successfully done with this technology. So this technique is found to be helpful for medicinal chemist in delivering new chemical entities and novel compounds. Furthermore, biomaterial science has also applied this technique to modify drug release properties through polymeric cross linkages and drug interaction to enhance drug dissolution.

This article discusses the different applications of Microwave assisted synthesis of organic polymeric compounds most thoroughly by focusing on aspects of speed, reproducibility and scalability. From this review it is clearly identified that independent on the type of organic material, data consistently points out to MW as a novel and powerful tool which has enable synthesis of a number of new compounds. From this review it is also identified that in organic chemistry the application of MW assisted irradiation is still a relatively new application and there is a need for the, the potential of this platform in organic chemistry science to be capitalized.

In future, the researchers will discover new microwave-assisted reactions to simplify the time consuming traditional approaches. Furthermore, suitable technologies will be developed in future to carry out microwave assisted reactions on industrial scales. As these technologies will involve with solvent free reaction protocols, they would be helpful to improvise the process and to reduce the environmental pollution. In the field of synthetic organic chemistry microwave assisted organic reactions are considered as an important tool as microwave technology could provide pure yields making it ideal for application of most other fields in future.

\section{References}

Armstrong, A., Brewer, J., Newman, C., Alakhov, V., Pietrzynski, G., Campbell, S., ... Valle, J. W. (2006). SP1049C as first-line therapy in advanced (inoperable or metastatic) adenocarcinoma of the oesophagus: a phase II window study. J. Clin. Oncol., 24, 4080.

Astrakas, L., Gousias, C., \& Tzaphlidou, M. (2011). Electric field effects on chignolin conformation. J. Appl Phys, 109, 94702. http://dx.doi.org/10.1063/1.3585867

Bacsa, B., Horvati, K., Bosze, S., Andreae, F., \& Kappe, C. O. (2008). Solid-phase synthesis of difficult peptide sequences at elevated temperatures - a critical comparison of microwave and conventional heating technologies. J. Org. Chem., 73, 7532-7542. http://dx.doi.org/10.1021/jo8013897

Besson, T., Guillard, J., \& Rees, C. W. (2000). Rapid synthesis of 2- cyanobenzothiazole, isothiocy. J. Chem. Soc., Perkin Trans, 1, 536-566.

Blokzijl, W., \& Engberts, J. B. F. N. (1993). Hydrophobic Effects. Opinions and Facts. Angew. Chem. Int., 32, 1545-1579. http://dx.doi.org/10.1002/anie.199315451

Bogda, D., Pielichowski, P., Borona, A. (1996). Remarkable Fast Microwave-Assisted N-Alkylation of Phthalimide in Dry Media. Synlett, 873-874.

Bogdal, D. (2005). Microwave assisted Organic Synthesis (p. 13). UK: Elsevier Publications.

Bogdal, D., Penczek, P., Pielichowski, J., \& Prociak, A. (2003). Microwave assisted synthesis, crosslinking, and processing of polymeric materials. Adv. Polym. Sci., 163, 193-263. http://dx.doi.org/10.1007/b11051

Bohr, H., \& Bohr, J. (2000). Microwave enhanced kinetics observed in ORD studies of a protein. Bioelectromagnetics, $\quad 21, \quad 68-72$. http://dx.doi.org/10.1002/(SICI)1521-186X(200001)21:1<68::AID-BEM10>3.0.CO;2-9

Bremer, R. E., Szewczyk, J. W., Baird, E. E., \& Dervan, P. B. (2000). Recognition of the DNA minor groove by pyrrole-imidazole polyamides: Comparison of desmethyl- and N-methylpyrrole. Bioorganic and Medicinal Chemistry, 8, 1947-1955. http://dx.doi.org/10.1016/S0968-0896(00)00145-0

Budi, A., Legge, F. S., Treutlein, H., \& Yarovsky, I. (2005). Electric field effects on insulin chain-B conformation. J. Phys Chem B, 109, 22641-8. http://dx.doi.org/10.1021/jp052742q

Budi, A., Legge, F. S., Treutlein, H., \& Yarovsky, I. (2007). Effect of frequency on insulin response to electric 
field stress. J. Phys Chem B, 111, 5748-5756. http://dx.doi.org/10.1021/jp067248g

Budi, A., Legge, F. S., Treutlein, H., \& Yarovsky, I. (2008). Comparative study of insulin chain-B in isolated and monomeric environments under external stress. $J$. Phys Chem B, 112, 7916-24. http://dx.doi.org/10.1021/jp800350v

Chen, J. J., \& Deshpande, S. V. (2003). Rapid synthesis of $\alpha$-ketoamides using microwave irradiation-simultaneous cooling method. Tetrahedron Lett, $44,8873$. http://dx.doi.org/10.1016/j.tetlet.2003.09.180

Chen, W. Y., \& Chen, Y. C. (2007). Acceleration of microwave-assisted enzymatic digestion reactions by magnetite beads. Anal Chem, 79, 2394-2401. http://dx.doi.org/10.1021/ac0614893

Dahmani, Z., Rahmouni, M., Brugidou, R., Bazureau, J. P., \& Hamelin, J. (1998). A new route to $\alpha$-hetero $\beta$-enamino esters using a mild and convenient solvent-free process assisted by focused microwave irradiation. Tetrahedron Lett., 39, 8453-8456.

Danson, S., Ferry, D., Alakhov, V., Margison, J., Kerr, D., Jowle, D., ... Ranson, M. (2004). Phase I dose escalation and pharmacokinetic study of pluronic polymer-bound doxorubicin (SP1049C) in patients with advanced cancer. Br J Cancer, 90, 2085-2091. http://dx.doi.org/10.1038/sj.bjc.6601856

De Pomerai, D. I., Smith, B., Dawe, A., North, K., Smith, T., Archer, D. B., ... Candido, E. P. M. (2003). Microwave radiation can alter protein conformation without bulk heating. FEBS Lett, 543, 93-97. http://dx.doi.org/10.1016/S0014-5793(03)00413-7

De Souza, R. O. M. A., Antunes, O. A. C., Kroutil, W., \& Kappe, C. O. (2009). Kinetic resolution of rac-1-phenylethanol with immobilized lipases: a critical comparison of microwave and conventional heating protocols. J. Org Chem, 74, 6157-6162. http://dx.doi.org/10.1021/jo9010443

Díaz-Ortiz, A., Prieto, P., \& Vázquez, E. (1997). Heck reactions under microwave irradiation in solvent-free conditions. Synlett, 269-270. http://dx.doi.org/10.1055/s-1997-774

Ebner, C., Bodner, T., Stelzer, F., \& Wiesbrock, F. (2011). One decade of microwave-assisted polymerizations: Quo vadis?. Macromolecular Rapid Communications, 32, 254-288. http://dx.doi.org/10.1002/marc.201000539

Edwards, W. F., Young, D. D., \& Deiters, A. (2009). The effect of microwave irradiation on DNA hybridization. Org Biomol Chem, 7, 2506-2508. http://dx.doi.org/10.1039/b903609a

Erdmenger, T., Guerrero-Sanchez, C., Vitz, J., Hoogenboom, R., \& Schubert, U. S. (2010). Recent developments in the utilization of green solvents in polymer chemistry. Chem Soc Rev, 39, 3317-3333. http://dx.doi.org/10.1039/b909964f

Gabriel, C., Gabriel, S., Grant, E. H., Halstead, B. S. J., \& Mingos, D. M. P. (1998). Dielectric parameters relevant to microwave dielectric heating. Chem Soc Rev, 27, 213-223. http://dx.doi.org/10.1039/a827213z

Glass, B. M., \& Combs, A. P. (2001). Rapid parallel synthesis utilizing microwave irradiation. In I. Sucholeiki (Ed.), High-Throughput Synthesis. Principles and Practices (pp. 123-128). New York: Marcel Dekker, Inc.

Guo, Y., Zhou, J., Song, Y., \& Zhang, L. (2009). An efficient and environmentally friendly method for the synthesis of cellulose carbamate by microwave heating. Macromolecular Rapid Communications, 30, 1504-1508. http://dx.doi.org/10.1002/marc.200900238

Gutmann, B., Obermayer, D., Reichart, B., Prekodravac, B., Irfan, M., Kremsner, J. M., \& Kappe, C. O. (2010). Sintered silicon carbide: a new ceramic vessel material for microwave chemistry in single-mode reactors. Chem Eur J, 16, 12182-94. http://dx.doi.org/10.1002/chem.201001703

Hahn, H. W., Rainer, M., Ringer, T., Huck, C. W., \& Bonn, G. K. (2009). Ultrafast microwave-assisted in-tip digestion of proteins. J Proteome Res, 8, 4225-30. http://dx.doi.org/10.1021/pr900188x

Hayes, B. L. (2004). Recent Advances in Microwave-Assisted Synthesis. Aldrichimica Acta, 37, 66-69.

Hayes, B. L., \& Collins, M. J. (2004). World Patent WO.

Heravi, M. M., Farhangi, N., Beheshtiha, Y. S., Ghassenizadeh, M., \& Tabar-Hydar, M. (2004). Sulfuric acid adsorbed on silica gel and chromium(VI) oxide: Rapid and selective oxida-tion of alcohol in solvent-free condition. Indian J. Chem, 43B, 430-431

Herrero, M. A., Kremsner, J. M., \& Kappe, C. O. (2008). Nonthermal microwave effects revisited: on the importance of internal reaction monitoring and agitation in microwave chemistry. J. Org Chem, 73, 36-47. 
http://dx.doi.org/10.1021/jo7022697

Hren, J., Kranjc, K., Polanc, S., \& Koevar, M. (2008). Aqueous versus Neat Reaction Conditions: The Microwave-Assisted, Selective Conversion of a Fused Anhydride Ring with Amines in the Presence of a Keto Group. Synthesis, 452-458.

Humphrey, C. E., Easson, M. A. M., Tierney, J. P., \& Turner, N. J. (2003). Solid-Supported Cyclohexane-1,3-dione (CHD): A "Capture and Release" Reagent for the Synthesis of Amides and Novel Scavenger Resin. Org. Lett, 5, 849. http://dx.doi.org/10.1021/o1027503p

Iannelli, M., \& Ritter, H. (2005) Microwave-assisted direct synthesis and polymerization of chiral acrylamide. Macromolecular Chemistry and Physics, 206, 349-353. http://dx.doi.org/10.1002/macp.200400422

Illman, D. L. (1994). Chemical process makes electrical "nanowires”. Chem. Eng. News, 72, 7.

Izquierdo, F. J., Alli, I., Yaylayan, V., \& Gómez, R. (2007). Microwave-assisted digestion of $\beta$-lactoglobulin by pronase, $\alpha$-chymotrypsin and pepsin. Int Dairy J., 17 , 465-70. http://dx.doi.org/10.1016/j.idairyj.2006.05.007

Juan, H. F., Chang, S. C., Huang, H. C., \& Chen, S. T. (2005). A new application of microwave technology to proteomics. Proteomics, 840-842. http://dx.doi.org/10.1002/pmic.200401056

Kappe, C. O. (2002). High-speed combinatorial synthesis utilizing microwave irradiation. Current Opinion in Chemical Biology, 6, 314-320.

Kappe, C. O. (2004). Controlled microwave heating in modern organic synthesis. Angew Chem Int Ed, 43, 6250-6284. http://dx.doi.org/10.1002/anie.200400655

Kappe, C. O., Kumar, D., \& Varma, R. S. (1999). Microwave-assisted high-speed parallel synthesis of 4-aryl-3,4-dihydropyrimidin-2(1H)-ones using a solventless Biginelli condensation protocol. Synthesis, 1799-1803. http://dx.doi.org/10.1055/s-1999-3592

Kappe, C. O., \& Stadler, A. (2005). Microwaves in Organic and Medicinal Chemistry.

Katritzky, A. R., Zhang, Y., Singh, S. K., \& Steel, P. J. (2003). 1,3-Dipolar cycloadditions of organic azides to ester or benzotriazolylcarbonyl activated acetylenic amides. Arkivoc, Volume 2003, Part (xv), 47-64.

Cotterill, I. C., Usyatinsky, A. Y., Arnold, J. M., Clark, D. S., Dordick, J. S., Michels, P. C., \& Khmelnitsky, Y. L. (1998). Microwave assisted combinatorial chemistry, Synthesis of substituted pyridines. Tetrahedron Lett, 39, 1117-1120. http://dx.doi.org/10.1016/S0040-4039(97)10796-1

Kirschner, E. M. (1994). Environment, Health Concerns Force Shift in Use of Organic Solvents. Chem. Eng. News, 72, 13-17.

Kirschning, A., Monenschein, H., \& Wittenberg, R. (2001). Functionalized polymers-Emerging versatile tools for solution-phase chemistry and automated parallel synthesis. Angewandte Chemie International Edition in English, 40 , 650-679. http://dx.doi.org/10.1002/1521-3773(20010216)40:4<650::AID-ANIE6500>3.0.CO;2-C

Kohn, J., Welsh, W. J., \& Knight, D. (2007). A new approach to the rationale discovery of polymeric biomaterials. Biomaterials, 28, 4171. http://dx.doi.org/10.1016/j.biomaterials.2007.06.022

Kremsner, J. M., \& Kappe, C. O. (2006). Silicon Carbide Passive Heating Elements in Microwave-Assisted Organic Synthesis. J. Org. Chem., 71, 4651. http://dx.doi.org/10.1021/jo060692v

La Cara, F., Scarfi, M. R., D'Auria, S., Massa, R., d'Ambrosio, G., Franceschetti G, ... De Rosa, M. (1999). Different effects of microwave energy and conventional heat on the activity of a thermophilic $\beta$-galactosidase from Bacillus acidocaldarius. Bioelectromagnetics, 20, 172-176. http://dx.doi.org/10.1002/(SICI)1521-186X(1999)20:3<172::AID-BEM3>3.0.CO;2-H

Langa, F., de la Cruz, P., de la Hoz, A., Díaz-Ortiz, A., \& Díez-Barra, E. (1997). Microwave irradiation: more than just a method for accelerating reactions Contemp. Org. Synth, 4, 373-386. http://dx.doi.org/10.1039/co9970400373

Larhed, M., \& Hallberg, A. (2001). Microwave-assisted high-speed chemistry: a new technique in drug discovery. Drug Discov Today, 6, 406-416. http://dx.doi.org/10.1016/S1359-6446(01)01735-4

Laurence, J. A., French, P. W., Lindner, R. A., \& McKenzie, D. R. (2000). Biological effects of electromagnetic fields - mechanism for the effects of pulsed microwave radiation on protein conformation. J. Theor Biol, 206, 291-8. http://dx.doi.org/10.1006/jtbi.2000.2123 
Lee, J., White, S. M., Gopalswamy, N., \& Kundu, M. R. (1997). Signatures of Coronal Currents in Microwave Images. Sol. Phys, 174, 175-190. http://dx.doi.org/10.1023/A:1004956422669

Lesur, A., Varesio, E., \& Hopfgartner, G. (2010) Accelerated tryptic digestion for the analysis of biopharmaceuticalmonoclonal antibodies in plasma by liquid chromatography with tandem mass spectrometric detection. J. Chromatogr A, 1217, 57-64. http://dx.doi.org/10.1016/j.chroma.2009.11.011

Li, A. (1993). Dough temperature change during mixing in a mixograph and a comparison of cake baking in conventional, impingment and hybrid ovens. Master's thesis, Dept.

Li, Y. C., Lin, Y. S., Tsai, P. J., Chen, C. T., Chen, W. Y., \& Chen, Y. C.(2007). Nitrilotriacetic acid-coated magnetic nanoparticles as affinity probes for enrichment of histidine-tagged proteins and phosphorylated peptides. Anal Chem., 79, 7519-25. http://dx.doi.org/10.1021/ac0711440

Lidström, J. P., \& Tierney (2005). Microwave-Assisted Organic Synthesis. Oxford: Blackwell Scientific.

Lidström, P., Tierney, J., Wathey, B. \& Westman, J. (2001). Microwave assisted organic synthesis-a review. Tetrahedron, 57, 9225-9283. http://dx.doi.org/10.1016/S0040-4020(01)00906-1

Lill, J. R. (2009). Microwave assisted proteomics. Cambridge: RSC Publishing.

Lill, J. R., Ingle, E. S., Liu, P. S., Pham, V., \& Sandoval, W. N. (2007) .Microwave-assisted proteomics. Mass Spectrometry Reviews, 26, 657-71. http://dx.doi.org/10.1002/mas.20140

Lo, C. Y., Chen, W. Y., Chen. C. T., \& Chen, Y. C. (2007). Rapid enrichment of phosphopeptides from tryptic digests of proteins using iron oxide nanocomposites of magnetic particles coated with zirconia as the concentrating probes. J. Proteome Res, 6, 887-93. http://dx.doi.org/10.1021/pr060333g

Mavandadi, F., \& Pilotti, A. (2006). The impact of microwave-assisted organic synthesis in drug discovery. Drug Discovery Today, 11(3-4), 165-174. http://dx.doi.org/10.1016/S1359-6446(05)03695-0.

Mingos, D. M. P., \& Whittaker, A. G. P., (1997). Microwave Dielectron Heating Effects in Chemical Synthesis. In R. V. Van Malik, \& C. D. Hubbard (Eds.), Chemistry under Extreme or Non-Classical Conditions (p. 479). New York and Heidelberg: John Wiley and Sons and Spektrum Akade-mischer Verlag Co-Publication.

Moreno, A., De La Hoz, A., \& Diaz-Ortiz, A. (2006). Selectivity under the action of microwave irradiation. In A. Loupy (Ed.), Microwaves in organic synthesis (p. 219-77, 2nd ed.). Weinheim:Wiley-VCH. http://dx.doi.org/10.1002/9783527619559.ch5

Moreno, A., De La Hoz, A., \& Diaz-Ortiz, A. (2005). Microwaves in organic synthesis. Thermal and non-thermal microwave effects. Chem Soc Rev, 34, 164-78. http://dx.doi.org/10.1039/b411438h

Moseley, J. D., Lenden, P., Thomson, A. D., \& Gilday, J. P. (2007). The importance of agitation and fill volume in small scale scientific microwave reactors. Tetrahedron Lett, 48, 6084-6087 http://dx.doi.org/10.1016/j.tetlet.2007.06.147

Nakamura, T., Nagahata, R., Kunii, K., Soga, H., Sugimoto, S., \& Takeuchi, K. (2010). Large-Scale Polycondensation of Lactic Acid Using Microwave Batch Reactors. Org. Process Res. Dev, 14, 781-786. http://dx.doi.org/10.1021/op900325e

Nikolić, R. J., Shao Q., Voss, L. F., Conway, A. M., Radev, R., Wang, T. F., ... Ericson, M. N. (2011) Invited, Si pillar structured thermal neutron detectors: Fabrication Challenges and Performance Expectations. SPIE Security and Defense Conference. Orlando, FL. http://dx.doi.org/10.1117/12.885880

Nóbrega, J A., Pirola, C., Fialho, L. L., Rota, G., de Campos Jordão, C. E., \& Pollo, F. (2012). Microwave-assisted digestion of organic samples: How simple can it become? Talanta, 98, 272-276. http://dx.doi.org/10.1016/j.talanta.2012.06.079

Nuchter, M., Ondruschka, B., Bonrath, W., \& Gum, A. (2004). Microwave assisted synthesis-a critical technology overview. Green Chem, 6, 128. http://dx.doi.org/10.1039/b310502d

Nuchter, M., Ondrushka, B., \& Lautenschlager, W. (2001) Microwave-Assisted Synthesis of Alkyl Glycosides. Synth. Commun, 37, 1277-1283. http://dx.doi.org/10.1081/SCC-100104035

Obermayer, D., Gutmann, B., \& Kappe, C. O. (2009). Microwave chemistry in silicon carbide reaction vials: separating thermal from nonthermal effects. Angew Chem Int $E d$, 48, 8321-4. http://dx.doi.org/10.1002/anie.200904185

Obermayer, D., \& Kappe, C. O. (2010). On the importance of simultaneous infrared/fiber-optic temperature monitoring in the microwave-assisted synthesis of ionic liquids. Org Biomol Chem, 8, 114-21. 
http://dx.doi.org/10.1039/b918407d

Öhlberg, L., \& Westman, J. (2001). An efficient and fast procedure for the Hantzsch dihydropyridine synthesis under microwave conditions. Synlett, 1296-1298. http://dx.doi.org/10.1055/s-2001-16043

Olsson, R., Hansen, H. C., \& Andersson, C. M. (2000). Microwave-assisted solvent-free parallel synthesis of thioamides. Tetrahedron Lett, 41, 7947-7950. http://dx.doi.org/10.1016/S0040-4039(00)01360-5

Pande, S., Singh, B. P., Mathur, R. B., Dhami, T. L., Saini, P., \& Dhawan, S. K. (2009). Improved Electromagnetic Interference Shielding Properties of MWCNT-PMMA Composites Using Layered Structures. Nanoscale Research Letters, 4, 327. http://dx.doi.org/10.1007/s11671-008-9246-x

Perreux, L., \& Loupy, A. (2001). A tentative rationalization of microwave effects in organic synthesis according to the reaction medium, and mechanistic considerations. Tetrahedron, 57, 9199-9223. http://dx.doi.org/10.1016/S0040-4020(01)00905-X

Perreux, L., \& Loupy, A. (2006). Nonthermal effects of microwaves in organic synthesis. In A. Loupy (Ed.), Microwaves in organic synthesis (pp. 134-218, 2nd ed.). Weinheim: Wiley-VCH. http://dx.doi.org/10.1002/9783527619559.ch4

Perreux, L., \& Loupy, A. A. (2001). A tentative rationalization of microwave effects in organic synthesis according to the reaction medium, and mechanistic considerations. Tetrahedron, 57, 9199-223. http://dx.doi.org/10.1016/S0040-4020(01)00905-X

Pileni, M. P. (1997). Nanosized Particles Made in Colloidal Assemblies, Langmuir, 13, 3266. http://dx.doi.org/10.1021/la960319q

Pon-On, W., Meejoo, S., \& Tang, I. (2007). Incorporation of iron into nano hydroxyapatite particles synthesized by the microwave process. Inter J Nanosci, 6, 9-16. http://dx.doi.org/10.1142/S0219581X07004262

Porcelli, M., Cacciapuoti, G., Fusco, S., Massa, R., d'Ambrosio, G., Bertoldo, C., ... Zappia, V. (1997). Non-thermal effects of microwaves on proteins: thermophilic enzymes as model system. med./biol. FEBS Lett , 1, 402(2-3), 102-106. http://dx.doi.org/10.1016/S0014-5793(96)01505-0

Prasad, D., Preetam, A. \& Nath, M. (2012). Microwave-assisted green synthesis of dibenzo[a,j]xanthenes using p-dodecylbenzenesulfonic acid as an efficient Bronsted acid catalyst under solvent-free conditions Original Research Article. Comptes Rendus Chimie, 15(8), 675-678. http://dx.doi.org/10.1016/j.crci.2012.05.018

Ramesh, P. D., Vaidyanatha, B., Ganguli, M., \& Rao, K. J. J. (1994). Synthesis of $\beta$-SiC powder by use of microwave radiation. J. Mater Res, 2, 3025.

Ravichandran, S., \& Karthikeyan, E. (2011). Microwave Synthesis-A Potential Tool for Green Chemistry. International Journal of Chem Tech Research, 3(1), 466-470.

Réjasse, B., Besson, T., Legoy, M. D., \& Lamare, S. (2006). Influence ofmicrowave radiation on free Candida antarctica lipase B activity and stability. Org Biomol Chem, 4, 3703-7. http://dx.doi.org/10.1039/b610265d

Réjasse, B., Lamare, S., Legoy, M. D., \& Besson, T. (2004). Stability improvement of immobilized Candida antarctica lipase B in an organic medium under microwave radiation. Org Biomol Chem, 2, 1086-9. http://dx.doi.org/10.1039/b401145g

Rejasse, B., Lamare, S., Legoy, M. D., \& Besson, T. (2007). Influence of microwave irradiation on enzymatic properties: applications in enzymatic chemistry. J. Enzyme Inhib Med Chem, 7(22), 518-26.

Roy, D., Ullah, A., \& Sumerlin, B. S. (2009). Rapid block copolymer synthesis by microwave-assisted RAFT polymerization. Macromolecules, 42, 7701-7708. http://dx.doi.org/10.1021/ma901471k

Sandoval, W. N., Pham, V. C., \& Lill, J. R. (2008). Recent developments in microwave-assisted protein chemistries - can this be integrated into the drug discovery and validation process? Drug Discov Today, 13, 1075-81. http://dx.doi.org/10.1016/j.drudis.2008.08.007

Sandoval, W. N., Pham, V., Ingle, E. S., Liu, P. S., \& Lill, J. R. (2007). Applications of microwave-assisted proteomics in biotechnology. Comb Chem High Throughput Screen, 10, 751-65. http://dx.doi.org/10.2174/138620707783018504

Santagada, V., Frecentese, F., Perissutti, E., Favretto, L., \& Caliendo, G. (2004). The application of microwaves in combinatorial andhigh-throughput synthesis as new synthetic procedure in drug discovery. QSAR Comb Sci, 23, 919-944. http://dx.doi.org/10.1002/qsar.200420039

Santagada, V., Frecentese, F., Perissutim E., Fiorino, F., Severino, B., \& Caliendo, G. (2009). Microwave assisted 
synthesis: a new technology in drug discovery. Review. Mini Rev Med Chem, 9, 340-358.

Scharn, D., Germeroth, L., Schneider-Mergener, J., \& Wenschuh, H. (2001). Sequential nucleophilic substitution on halogenated triazines, pyrimidines, and purines: a novel approach to cyclic peptidomimetics. J. Org Chem, 66, 507-513. http://dx.doi.org/10.1021/jo005631q

Seijas, A., \& Vazquez-Tato, M. P. (2007). Microwaves: a new tool for an ancient element. Solvent and support-free Microwave-assisted organic synthesis. Chimica Oggi., 25, 20-26.

Seijas, J. A., Vazquez-Tato, M. P., Martinez, M. M., \& Corredoira, G. N. (1999). Direct Synthesis of Imides from Dicarboxylic Acids using Microwaves. J. Chem. Res, 420-425.

Sekhon, R. K., Schilling, M. W., Phillips, T. W., Hasan, M. M., Aikens, M. J., Nannapaneni, R., \& Mikel, W. B. (2010). Effects of carbon dioxide and ozone treatments on the volatile composition and sensory quality of dry cured ham. J. Food Science, 75(5), 452-458. http://dx.doi.org/10.1111/j.1750-3841.2010.01646.x

Sosnik, A., Gotelli, G., \& Abraham, G. A. (2010). Microwave-assisted polymer synthesis (MAPS) as a tool in biomaterials science: How new and how powerful. Progress in Polymer Science, 36, 1050-1078. http://dx.doi.org/10.1016/j.progpolymsci.2010.12.001

Stadler, A., \& Kappe, C. O. (2001). Automated library generation using sequential microwave-assisted chemistry, Application toward the Biginelli multicomponent condensation. J. Comb Chem, 3, 624-630. http://dx.doi.org/10.1021/cc010044j

Strauss, C. R., \& Trainor, R. W. (1995). Developments in microwave-assisted organic chemistry. Aust. J. Chem, 48, 1665-1692. http://dx.dot.org/10.1071/CH9951665

Strohmeier, G. A., \& Kappe, C. O. (2002). Rapid parallel synthesis of polymer bound enones utilizing microwave-assisted solid-phase chemistry. J. Comb Chem, 4. 154-161. http://dx.doi.10.1021/cc010043r

Sun, W., Gao, S., Wang, L., Chen, Y., \& Wu, S. (2005). Microwave-assisted protein preparation and enzymatic digestion in proteomics. Mol Cell Proteomics, 5, 769-76. http://dx.doi.org/10.1074/mcp.T500022-MCP200

Surati, M. A., Jauhari, S. A., \& Desai, K. R. (2012). A brief review: Microwave assisted organic reaction. Archives of Applied Science Research, 4(1), 645-661.

Tsoleridis, C. A., Neochoritis, C. G., Tzitzikas, T., Stephanidou-Stephanatou, J., Kontogiorgis, C. A., Hadjipavlou-Litina, D. J., \& Choli-Papadopoulou, T. (2011). One-pot microwave assisted synthesis under green chemistry conditions, antioxidant screening, and cytotoxicity assessments of benzimidazole Schiff bases and pyrimido[1,2-a]benzimidazol-3(4H)-ones. European Journal of Medicinal Chemistry, 46(1), 297-306.

Tucker, J. L. (2010). Green chemistry: cresting a summit toward sustainability. Org Process Res Dev, 14, 328-331. http://dx.doi.org/10.1021/op9000548

Usyatinsky, A. Y., \& Khmelnitsky, Y. L. (2000). Microwave-assisted synthesis of substituted imidazoles on a solid support under solvent-free conditions. Tetrahedron Lett, 41, 5031-5034. http://dx.doi.org/10.1016/S0040-4039(00)00771-1

Vaezzadeh, A. R., Deshusses, J. M. P., Waridel, P., Francois, P., Zimmermann-Ivol, C. G., Lescuyer, P., ... Hochstrasser, D. F. (2010). Accelerated digestion for high-throughput proteomics analysis of whole bacterial proteomes. J Microbiol Methods, 80, 56-62. http://dx.doi.org/10.1016/j.mimet.2009.10.019

Varma, R. A. (2001). Solvent-free accelerated organic syntheses using microwaves. Pure Appl. Chem, 73, 193-197.

Varma, R. S., \& Kumar, D. (1999). Microwave-accelerated three-component condensation reaction on clay: solvent-free synthesis of imidazo[1,2-a] annulated pyridines, pyrazines and pyrimidines. Tetrahedron Lett, 40, 7665-7669. http://dx.doi.org/10.1016/S0040-4039(99)01585-3

Varma, Rr. S. (2006). Greener Organic Syntheses Under Non-Traditional Conditions. Indian J. Chem.; Sec. B, $45 B, 2305-2307$.

Wang, L. K., Li, L., Li, X. M., Shi, Y. H., Hu, L., \& Le, G. W. (2008). Microwave assisted solid state reaction synthesis of methionine complexes of iron (II). Food Chemistry, 106, 315-323. http://dx.doi.org/10.1016/j.foodchem.2007.04.075

Wang, S., Cheng, C., Wu, F., Jiang, B., Shi, F., Tu, S., ... Li, G. (2011). Microwave-assisted multi-component reaction in water leading to highly regioselective formation of benzo[f]azulen-1-ones. Tetrahedron, 67(25), 
4485-4493. http://dx.doi.org/10.1016/j.tet.2011.05.002

Wathey, B., Tierney, J., Lidström, P., \& Westman, J. (2002). The impact of microwave-assisted organic chemistry on drug discovery Review Article. Drug Discovery Today, 7(6), 373-380. http://dx.doi.org/10.1016/S1359-6446(02)02178-5

Wenschuh, H., Scharn, D., Reineke, U., Schneider-Mergener, J., \& Germeroth, L. (2000). Spatially addressed synthesis of amino- and aminooxy-substituted 1,3,5-triazine arrays on polymeric membranes. J Comb Chem, 2, 361-369. http://dx.doi.org/10.1021/cc000012g

Williams, D. F. (2009). On the nature of biomaterials. Biomaterials, 30, 5897-909.

Wilson, N. S., Sarko, C. R., \& Roth, G. P. (2002). Microwave-assisted synthesis of 2-aminoquinolones. Tetrahedron Lett, 43, 581-583. http://dx.doi.org/10.1016/S0040-4039(01)02242-0

Wilson, N. S., Sarko, C., \& Roth, G. (2001). Microwave-assisted synthesis of a [3+2] cycloaddition library. Tetrahedron Lett, 42, 8939-8941. http://dx.doi.org/10.1016/S0040-4039(01)01986-4

Xu, Q., Chao, B., Wang, Y. D., \& Dittmer, C. D. (1997). Tellurium in the "no-solvent" organic synthesis of allylic alcohols. Tetrahedron, 53, 12131-21346.

Xu, Q., Zhang, C., Cai, S., Zhu, P., \& Liu, L. (2010). Large-scale microwave-assisted ring-opening polymerization of e-caprolactone. J. Ind Eng Chem, 16, 872-5.

Xu, X., Yang, W., Liu, J., \& lin, L. (2000). Synthesis of a High-Permeance NaA Zeolite Membrane by $\begin{array}{lllll}\text { Microwave Heating. } & \text { Adv } & \text { 195-198. }\end{array}$ http://dx.doi.org/10.1002/(SICI)1521-4095(200002)12:3<195::AID-ADMA195>3.0.CO;2-E

Yadav, G. D., \& Borkar, I. V. (2009). Kinetic and mechanistic investigation of microwave-assisted lipase catalyzed synthesis of citronellyl acetate. Ind Eng Chem Res, 48, 7915-22. http://dx.doi.org/10.1021/ie800591c

Young, D. D., Nichols, J., Kelly, R. M., \& Deiters, A. (2008). Microwave activation of enzymatic catalysis. $J$ Am Chem Soc, 130, 10048-9. http://dx.doi.org/10.1021/ja802404g

Zhang, H., He, X., \& He, F. (2009). Microstructure and physicochemical properties of ambient dried SiO2 aerogels with K2Ti6O13 whisker additive. J. Alloys Compounds, 472, 194-197. http://dx.doi.org/10.1016/j.jallcom.2008.04.032

Zhao, H. (2010). Microwave-assisted enzymatic reactions in aqueous media. In V. Polshettiwar, \& R. S. Varma (Eds.), Aqueous microwave assisted chemistry (pp. 123-44). Cambridge: RSC Publishing. http://dx.doi.org/10.1039/9781849730990-00123 